\title{
In Vivo Expression of Reprogramming Factors Increases Hippocampal Neurogenesis and Synaptic Plasticity in Chronic Hypoxic-Ischemic Brain Injury
}

\author{
Soohyun Wi, ${ }^{1,2}$ Ji Hea Yu, ${ }^{1,2}$ MinGi Kim, ${ }^{1,2}$ and Sung-Rae Cho ${ }^{1,2,3,4}$ \\ ${ }^{1}$ Department and Research Institute of Rehabilitation Medicine, Yonsei University College of Medicine, Seoul 03722, Republic of Korea \\ ${ }^{2}$ Brain Korea 21 PLUS Project for Medical Science, Yonsei University College of Medicine, Seoul 03722, Republic of Korea \\ ${ }^{3}$ Rehabilitation Institute of Neuromuscular Disease, Yonsei University College of Medicine, Seoul 03722, Republic of Korea \\ ${ }^{4}$ Yonsei Stem Cell Research Center, Avison Biomedical Research Center, Seoul 03722, Republic of Korea
}

Correspondence should be addressed to Sung-Rae Cho; srcho918@yuhs.ac

Received 17 June 2016; Revised 25 August 2016; Accepted 21 September 2016

Academic Editor: Yong Jeong

Copyright (C) 2016 Soohyun Wi et al. This is an open access article distributed under the Creative Commons Attribution License, which permits unrestricted use, distribution, and reproduction in any medium, provided the original work is properly cited.

\begin{abstract}
Neurogenesis and synaptic plasticity can be stimulated in vivo in the brain. In this study, we hypothesized that in vivo expression of reprogramming factors such as Klf4, Sox2, Oct4, and $c-M y c$ would facilitate endogenous neurogenesis and functional recovery. $\mathrm{CD}-1^{\circledR}$ mice were induced at 1 week of age by unilaterally carotid artery ligation and exposure to hypoxia. At 6 weeks of age, mice were injected GFP only or both four reprogramming factors and GFP into lateral ventricle. Passive avoidance task and open field test were performed to evaluate neurobehavioral function. Neurogenesis and synaptic activity in the hippocampus were evaluated using immunohistochemistry, qRT-PCR, and/or western blot analyses. Whereas BrdU ${ }^{+} \mathrm{GFAP}^{+}$cells in the subgranular zone of the hippocampus were not significantly different, the numbers of $\mathrm{BrdU}^{+} \beta \mathrm{III}$-tubulin ${ }^{+}$and $\mathrm{BrdU}^{+} \mathrm{NeuN}^{+}$cells were significantly higher in treatment group than control group. Expressions of synaptophysin and PSD-95 were also higher in treatment group than control group. Importantly, passive avoidance task and open field test showed improvement in long-term memory and decreased anxiety in treatment group. In conclusion, in vivo expression of reprogramming factors improved behavioral functions in chronic hypoxic-ischemic brain injury. The mechanisms underlying these repair processes included endogenous neurogenesis and synaptic plasticity in the hippocampus.
\end{abstract}

\section{Introduction}

The strongly established idea that the adult brain has no ability for generating new neurons is now controverted, and recent studies have discovered that the adult mammalian brain can generate new neurons $[1,2]$. Even though many studies had a doubt in this idea for a long time, it is now established as the new idea that throughout adult life in many species, including humans, specific regions of the brain continuously generate new neurons $[2,3]$. In two regions of the adult brain, adult neurogenesis has been constantly observed. Namely, in the subventricular zone (SVZ) of the lateral ventricle and the subgranular zone of the hippocampus, the adult neurogenesis is generated from neural stem cells (NSCs) [4]. Previous researches in the past decade have clarified procedures of adult neurogenesis, such as the proliferation and the fate determination of NSCs, differentiation and maturation of neurons, and the eventual integration of neurons into the neural networks $[2,5]$.

The presence of NSCs and the existence of new neurons at certain regions in the adult brain suggest that it may treat incurable neurological diseases by inducing neurogenesis [6]. Previous studies with animal models have also shown that new neural progenitor cells, which have possibility to migrate and effect on damaged regions, are produced at the SVZ [68]. Other studies have confirmed that, even at the adult brain, neurogenesis occurred in both the SVZ and subgranular zone of the hippocampus following cerebral ischemia. When the brain has ischemic damage, neuronal precursors of the SVZ and subgranular zone move to the damaged sites [6, 9-11]. 


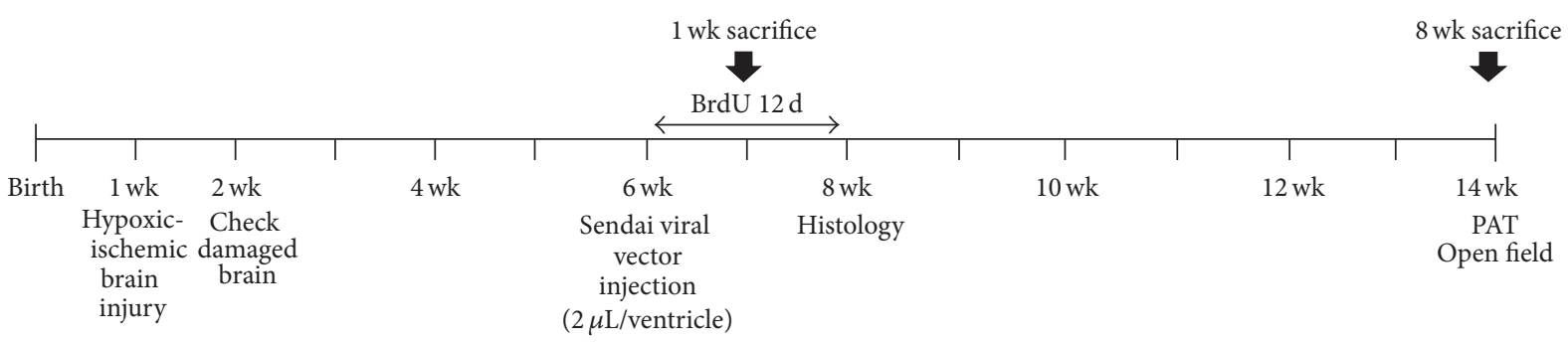

(a)

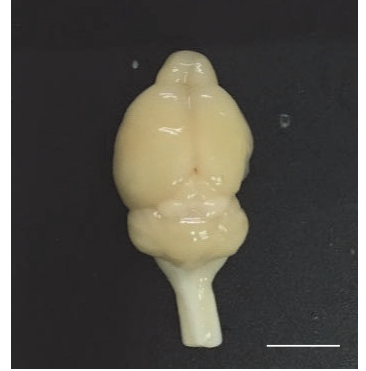

(b)

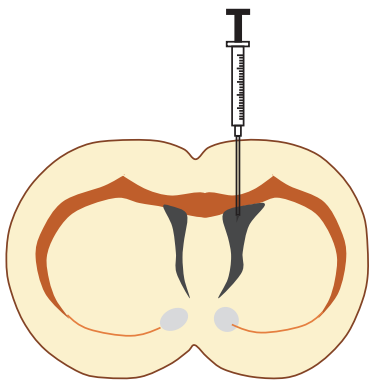

(c)

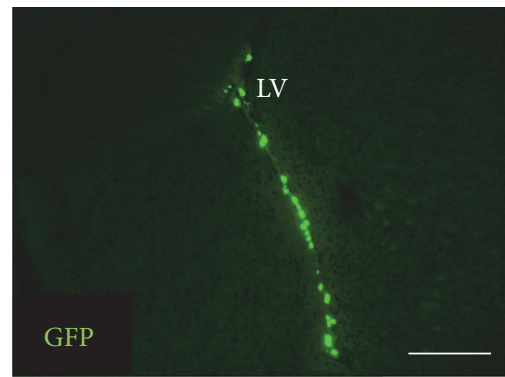

(d)

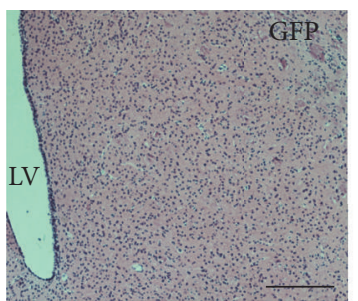

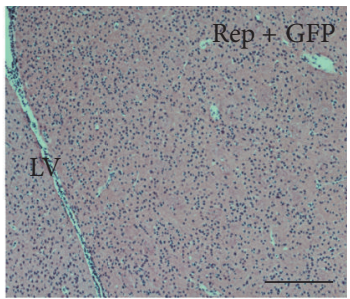

(e)
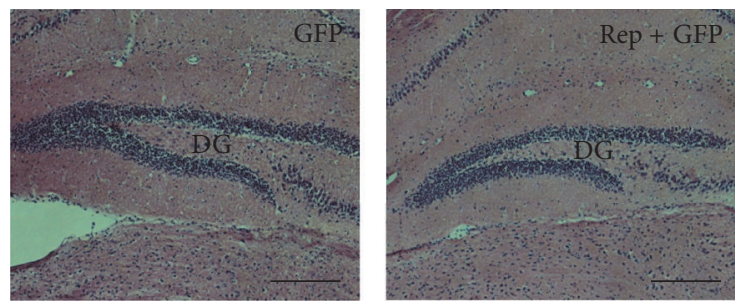

(f)

FIGURE 1: Experimental design and intraventricular injection of reprogramming factors. (a) Schematic timeline of the experiment. (b) A brain picture of chronic hypoxic-ischemic brain injury model. Scale bar $=0.5 \mathrm{~cm}$. (c) At postnatal 6 weeks, mice were injected in the right side of lateral ventricle with GFP and the four reprogramming factors, that is, Oct4, Sox2, c-Myc, and Klf4 (treatment group), or GFP only (control group). (d) An image of GFP expression in the lateral ventricle. Scale bar $=200 \mu \mathrm{m}$. (e) Absence of dysplasia or tumor development in the lateral ventricle. (f) Absence of dysplasia or tumor development in the hippocampus. Both samples of (e) and (f) were evaluated 8 weeks after the treatment, and brain sections were stained with hematoxylin and eosin and observed using a microscope. Neither dysplasia nor tumors were observed in any group. Scale bars $=200 \mu \mathrm{m}$. PAT, passive avoidance task; LV, lateral ventricle; DG, dentate gyrus.

Understanding the molecular control of endogenous NSC activation and progenitor cell mobilization will likely give various chances for the use of stimulated neuronal replacement as a therapeutic approach $[6,12]$. However, compensatory neurogenesis stimulated after brain injury is basically limited, so it is now obvious that endogenous neurogenesis should not be an individual concern for complete functional recovery $[6,13]$.

Previous study has been reported that reprogramming factors such as Oct4, Sox2, c-Myc, and Klf4 can convert fibroblasts into pluripotent stem cells [14]. Enhanced cell proliferation is the most noticeable and earliest response when the reprograming factors are expressed [15]. This enhanced proliferation is associated with the induction of proliferative genes [16]. According to this observation, we suggested that the in vivo expression of the four reprogramming factors listed above would support in vivo cell proliferation in the hippocampus and SVZ, a major process for recovery from chronic hypoxic-ischemic brain injury.

\section{Materials and Methods}

2.1. Animals and Housing. All animals were housed in a standard cage $\left(27 \times 22.5 \times 14 \mathrm{~cm}^{3}\right)$ in a facility accredited by the Association for Assessment and Accreditation of Laboratory Animal Care (AAALAC) and provided food and water ad libitum with alternating 12-hour light/dark cycles, according to animal protection regulations. The experimental procedures were approved by the Institutional Animal Care and Use Committee (IACUC number 2016-0109 and number 2016-0070). A schematic timeline of this experiment from birth to 14 weeks of age is provided in Figure 1(a).

2.2. Neonatal Hypoxic-Ischemic Brain Injury. Permanent ischemic brain damage was induced in 7-day-old CD-1 (ICR) mice (Orient, Seongnam, Korea), by unilateral right carotid artery ligation. Hypoxic brain injury ( $8 \% \mathrm{O}_{2}$ for 60 minutes) was also induced as described previously [17-20]. Animals with severe brain lesions covering more than $50 \%$ of the 
unilateral hemisphere were excluded from the criteria. Atmosphere around mice was maintained at $37^{\circ} \mathrm{C}$ within the hypoxic chamber. Neonatal hypoxic-ischemic brain injury model is shown in Figure 1(b).

2.3. Intraventricular Injection of Reprogramming Factors. At 6 weeks of age, a total of 32 mice were anesthetized with ketamine $(100 \mathrm{mg} / \mathrm{kg}$; Huons, Gyeonggi-do, Korea) and xylazine (10 mg/kg; Bayer Korea, Seoul, Korea) by intraperitoneal (IP) injection and were randomly assigned to either the control group (green fluorescent protein (GFP) only, $n=15$ ) or the treatment group (Oct4, Sox2, c-Myc, and Klf4, and GFP, $n=$ 15). Mice received intraventricular injection of GFP $(1.5 \times$ $10^{6} \mathrm{CIU} / \mathrm{mL}, 2 \mu \mathrm{L}$ volume, and $0.01 \mu \mathrm{L} / \mathrm{s}$ infusion rate; ThermoFisher, Carlsbad, CA, USA) only or both GFP and four reprogramming factors $\left(1.5 \times 10^{6} \mathrm{CIU} / \mathrm{mL}, 2 \mu \mathrm{L}\right.$ volume, and $0.01 \mu \mathrm{L} / \mathrm{s}$ infusion rate; CytoTune ${ }^{\mathrm{TM}}$-iPS 2.0 Sendai Reprogramming Kit, ThermoFisher, Carlsbad, CA) using stereotaxic coordinates (AP $+0.5 \mathrm{~mm}$ from bregma; $\mathrm{ML}-0.7 \mathrm{~mm}$ from bregma; DV $-2.0 \mathrm{~mm}$ from dura) (Figure 1(c)). Mice had recovered in a heating chamber at $37^{\circ} \mathrm{C}$ after the surgical treatment.

2.4. Passive Avoidance Task. To evaluate memory function based on learning to avoid an aversive stimulus, a 2-compartment step-through passive avoidance task (PAT) was conducted [21-23]. The method was adapted from the previous study for examination of the long-term memory [23].

2.5. Open Field Test. Open field test is generally used to evaluate locomotor activity and spontaneous exploration in a novel environment $[24,25]$. Activity monitoring was conducted in a square area measuring $30 \times 30.5 \times 31 \mathrm{~cm}^{3}$. The area's floor was divided into 16 sectors. The 4 inner sectors marked out the center, while the 12 outer sectors were defined as the periphery. Total distance in the center was recorded as an index of anxiety [26, 27]. Mice were placed individually into the periphery of the area and were allowed to explore freely for 15 minutes while being monitored with a video camera. The resulting data were analyzed using the video tracking system Smart Vision 2.5.21 (Panlab, Barcelona, Spain).

2.6. Immunohistochemistry. This method was adapted from the previous study [17]. Immunohistochemistry was performed as described previously [17]. Briefly, animals were euthanized and perfused with $4 \%$ paraformaldehyde (PFA). Harvested brain tissues were cryosectioned with a slice thickness of $16 \mu \mathrm{m}$ and immunohistochemistry staining was performed on 4 sections. All animals received an IP injection of 5-bromo-2-deoxyuridine (BrdU) $(50 \mathrm{mg} / \mathrm{kg})$ once a day for 12 days, beginning 1 day after stereotaxic surgery, to evaluate endogenous cell genesis and neurogenesis in the subgranular zone of the hippocampus and SVZ. Eight weeks after the treatment, the long-term survival of newly generated neurons was evaluated in 3 mice from each of the control and treatment groups ( $n=3$ per group). Sections were stained with primary antibodies against $\mathrm{BrdU}(1: 200$, Abcam, Cambridge, UK), $\beta$ III-tubulin (1:400, Covance, Princeton, NJ, USA), glial fibrillary acidic protein (GFAP) (1:400, Abcam),
Nestin (1:400, Abcam), synaptophysin (1:100, Abcam), and postsynaptic density protein 95 (PSD-95) (1:100, Abcam) and secondary antibodies such as Alexa Fluor ${ }^{\circledR} 488$ goat anti-rat (1:400, Invitrogen, Carlsbad, CA, USA), Alexa Fluor 568 goat anti-rabbit (1:400, Invitrogen), and Alexa Fluor 594 goat anti-mouse $(1: 400$, Invitrogen). Stained sections were then mounted on glass slides with fluorescent mounting medium containing 4',6-diamidino-2-phenylindole (DAPI; Vectashield, Vector, Burlingame, CA, USA). Stained sections were analyzed using confocal microscopy (LSM700, Zeiss, Gottingen, Germany). Images of GFP expression in the lateral ventricle were taken using a fluorescent microscope (Axio Imager M2, Zeiss) and density was evaluated using ZEN Imaging Software (blue edition, Zeiss).

2.7. Western Blot Analysis. This method was adapted from the previous study [17]. To confirm the expression of synaptophysin and PSD-95 in the hippocampus in the control and treatment groups ( $n=3$ per group), $50 \mu$ g extracted proteins were dissolved in sample buffer $(60 \mathrm{mM}$ Tris- $\mathrm{HCl}, \mathrm{pH} 6.8$, $14.4 \mathrm{mM}$ b-mercaptoethanol, $25 \%$ glycerol, $2 \%$ SDS, and $0.1 \%$ bromophenol blue; Invitrogen), incubated for 10 minutes at $70^{\circ} \mathrm{C}$, and separated on a $10 \%$ SDS reducing polyacrylamide gel (Invitrogen). Separated proteins were then equally loaded and transferred onto polyvinylidene difluoride membranes (Invitrogen) using a Trans-Blot System (Novex ${ }^{\circledR}$ Mini-Cell; Invitrogen). Blots were blocked for 1 hour in Tris-buffered saline (TBS) (10 mM Tris- $\mathrm{HCl}, \mathrm{pH} 7.5$, and $150 \mathrm{mM} \mathrm{NaCl})$ containing 5\% nonfat dry milk (Bio-Rad) at room temperature, washed three times with TBS, and incubated at $4^{\circ} \mathrm{C}$ overnight with a synaptophysin $(1: 1,000$, Abcam) antibody and a PSD-95 (1:1,000, Abcam) antibody in TBST (10 mM Tris, pH 7.5, $150 \mathrm{mM} \mathrm{NaCl}$, and $0.02 \%$ Tween 20 ) containing $3 \%$ nonfat dry milk. The next day, blots were washed three times with TBST and incubated for 1 hour with horseradish peroxidase-conjugated secondary antibodies $(1: 3,000$, Santa Cruz Biotechnology, Santa Cruz, CA, USA) at room temperature. A housekeeping gene was evaluated with actin-antibody (1:1,000, Santa Cruz Biotechnology). After washing three times with TBST, blots were visualized with an ECL detection system (Amersham Pharmacia Biotech, Little Chalfont, UK). Using ImageQuant ${ }^{\mathrm{TM}}$ LAS 4000 software (GE Healthcare Life Science, Chicago, IL, USA), western blot results were saved into TIFF image files, and then the images were analyzed using Multi-Gauge (Fuji Photo Film, version 3.0, Tokyo, Japan).

2.8. Quantitative Real-Time Reverse Transcription-Polymerase Chain Reaction ( $q R T-P C R)$. cDNAs were synthesized from sample RNAs with ReverTra Ace ${ }^{\circledR}$ qPCR RT Master Mix with gDNA Remover (TOYOBO, Osaka, Japan). Then, $5 \mu \mathrm{L}$ of cDNA in a total volume of $20 \mu \mathrm{L}$ was used in the following reaction. The following steps of qRT-PCR are the same as the previous study [28]. The primers were as follows: mouse PSD-95, 5'-TCCCCATTTTCTCCCACACAC- ${ }^{\prime}$ and $5^{\prime}$-ACGGCGTGGGGAGTTATGAT-3'; mouse synaptophysin, $5^{\prime}$-GTGCCAACAAGACGGAGAGT-3' and $5^{\prime}$ CACCCGAGGAGGAGTAGTCA-3'; mouse glyceraldehyde 


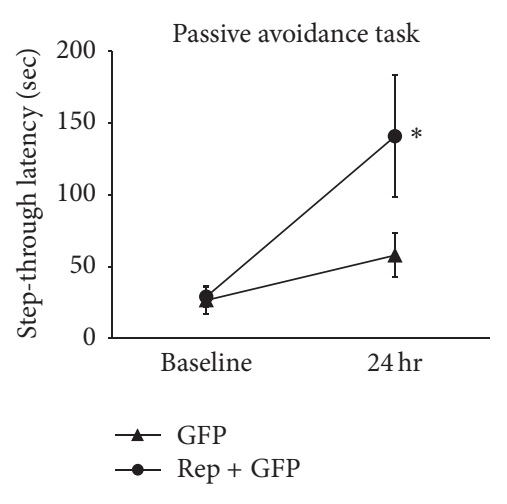

(a)

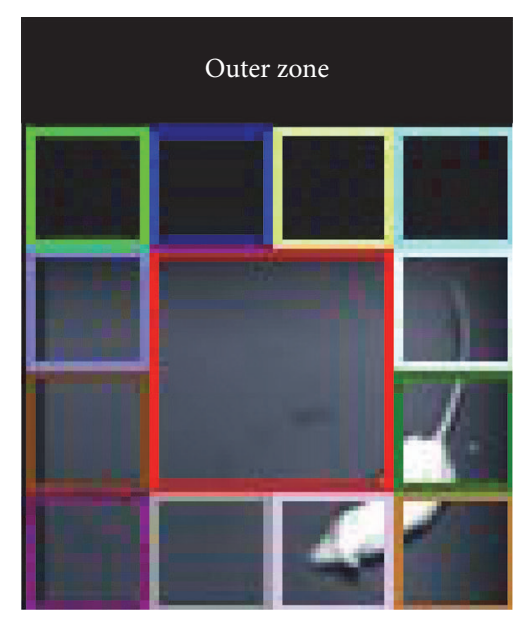

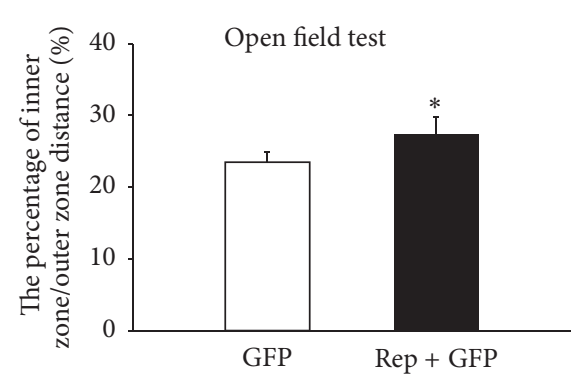

(b)

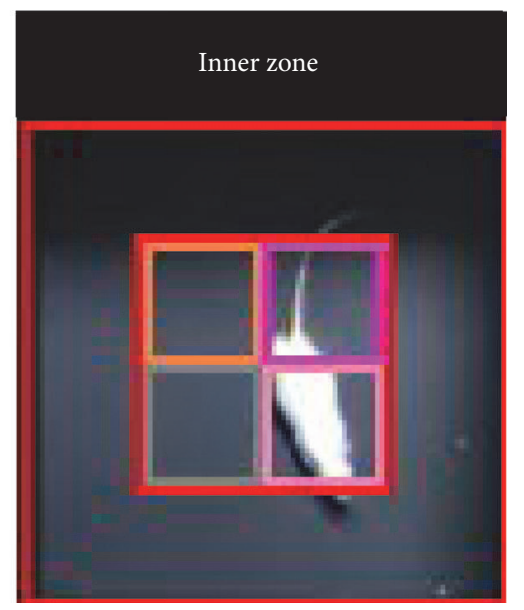

(c)

FIGURE 2: Effects of reprogramming factor expression on neurobehavioral functions after chronic hypoxic-ischemic brain injury. Passive avoidance task and open field test results showed that expression of the four reprogramming factors improved long-term memory and decreased anxiety 8 weeks after the treatment. (a) Expression of the four reprogramming factors significantly improved retention test performance 24 hours after an aversive stimulus 8 weeks after the treatment (140.9 \pm 42.5 seconds) relative to that in the initial assessment ( $57.9 \pm 15.3$ seconds), whereas the performance was not statistically improved in the control group $(t=2.916, p<0.05 ; n=7$ per group). The result suggests that the expression of reprogramming factors improves long-term memory 8 weeks after the treatment. (b) The total distance of movement was assessed for $15 \mathrm{~min}$. The percentage of the inner zone/outer zone increased in the treatment group (27.4 $\pm 1.3 \%)$ compared to the control group $(23.5 \pm 1.1 \%)(t=2.568, p<0.05 ; n=8$ and $n=9$ per group, resp.). (c) Among the total of 16 zones, 4 central zones are an inner zone, and 12 peripheral zones are an outer zone. ${ }^{*} p<0.05$.

3-phosphate dehydrogenase (GAPDH), 5'-CATCACTGCCACCCAGAAGACTG- ${ }^{\prime}$ and $5^{\prime}$-ATGCCAGTGAGCTTCCCGTTCAG-3'. GAPDH was used as the internal control.

2.9. Statistical Analyses. The numbers of $\mathrm{BrdU}^{+}$cells, $\mathrm{BrdU}^{+} \beta \mathrm{III}$ tubulin ${ }^{+}$cells, $\mathrm{BrdU}^{+} \mathrm{NeuN}^{+}$cells, and $\mathrm{BrdU}^{+} \mathrm{GFAP}^{+}$cells in the hippocampus, the level of synaptic proteins such as synaptophysin and PSD-95, and open field test results were analyzed between the treatment and control groups using independent $t$-test as implemented in SPSS (version 18.0; Armonk, NY, USA). Neurobehavioral outcome for passive avoidance task was compared between baseline and 24 hours using paired $t$-test. Statistical significance was accepted when $p<0.05$.

\section{Results}

3.1. In Vivo Reprogramming Factor Expression Improves LongTerm Memory after Chronic Hypoxic-Ischemic Brain Injury. To determine whether the in vivo expression of four reprogramming factors improved cognitive function, passive avoidance task was performed before the surgical treatment and 8 weeks after intervention in the control and treatment groups ( $n=7$ per group). Expression of the reprogramming factors significantly improved retention test performance 24 hours after an aversive stimulus at 8 weeks after the treatment $(140.9 \pm 42.5$ seconds) relative to that in the initial assessment (57.9 \pm 15.3 seconds) $(t=2.916, p<0.05)$, whereas the performance was not statistically improved in the control group (Figure 2(a)). The result suggests that in vivo expression 
TABLE 1: Newly generated neurons in the hippocampus and subventricular zone after the in vivo expression of reprogramming factors. To identify newly generated cells, mice were injected daily with BrdU up to 12 days. Eight weeks after the treatment, histological evaluations were performed.

\begin{tabular}{|c|c|c|c|c|c|c|}
\hline \multirow[b]{2}{*}{ Group } & \multicolumn{3}{|c|}{ Hippocampus } & \multicolumn{3}{|c|}{ Subventricular zone } \\
\hline & $\begin{array}{c}\text { BrdU }^{+} \\
\left(\times 10^{3} \text { cells } / \mathrm{mm}^{3}\right)\end{array}$ & $\begin{array}{c}\text { BrdU }^{+} \beta \text { III-tubulin } \\
\left(\times 10^{3} \text { cells } / \mathrm{mm}^{3}\right) \\
\end{array}$ & $\begin{array}{c}\mathrm{BrdU}^{+} \mathrm{NeuN}^{+} \\
\left(\times 10^{3} \text { cells } / \mathrm{mm}^{3}\right)\end{array}$ & $\begin{array}{c}\mathrm{BrdU}^{+} \\
\left(\times 10^{3} \text { cells } / \mathrm{mm}^{3}\right)\end{array}$ & $\begin{array}{c}\text { BrdU }^{+} \text {Nestin } \\
\\
\left(\times 10^{3} \text { cells } / \mathrm{mm}^{3}\right)\end{array}$ & $\begin{array}{c}\mathrm{BrdU}^{+} \mathrm{GFAP}^{+} \\
\left(\times 10^{3} \text { cells } / \mathrm{mm}^{3}\right) \\
\end{array}$ \\
\hline GFP & $8.1 \pm 2.0$ & $3.0 \pm 1.6$ & $2.1 \pm 1.6$ & $29.6 \pm 7.4$ & $3.6 \pm 1.5$ & $5.7 \pm 2.0$ \\
\hline Rep + GFP & $17.6 \pm 1.9^{*}$ & $9.2 \pm 2.3^{*}$ & $13.2 \pm 5.1^{*}$ & $57.7 \pm 4.1^{* *}$ & $15.3 \pm 2.6^{* *}$ & $16.5 \pm 4.8^{*}$ \\
\hline Fold change & 2.2 & 3.1 & 6.2 & 2.0 & 4.3 & 2.9 \\
\hline
\end{tabular}

BrdU, 5-bromo-2-deoxyuridine; GFP, green fluorescent protein; Rep, reprogramming factors.

${ }^{*} p<0.05,{ }^{* *} p<0.01$, and $n=3$ per group.

of reprogramming factors improves long-term memory 8 weeks after the treatment. Additionally, when the stepthrough latency was evaluated in the passive avoidance task, there was no significant difference between sham-operated control group (205.7 \pm 55.7 seconds) and treatment group ( $235.7 \pm 45.7$ seconds) ( $n=6$ per group; Figure S2A in Supplementary Material available online at http://dx.doi.org/10.1155/ 2016/2580837).

3.2. In Vivo Expression of Reprogramming Factors Decreases Anxiety in Chronic Hypoxic-Ischemic Brain Injury. To evaluate the effect of the four reprogramming factors on anxiety, the results of open field test, 8 weeks after intervention, were compared between the treatment and control groups $(n=8$ and 9 per group, resp.). The total zone was divided into the outer zone and inner zone (Figure 2(c)). The percentage of the inner zone/outer zone increased after the in vivo expression of the four reprogramming factors in the treatment group $(27.4 \pm 1.3 \%)$ compared to the control group $(23.5 \pm 1.1 \%)$ $(t=2.568, p<0.05$; Figure 2(b)). When a ratio of distance of inner zone over outer zone decreases, this ratio can be the indication of the reduction of anxiety [27]. Therefore, this result suggests that the in vivo expression of reprogramming factors decreased anxiety-related behavior. Additionally, when the percentage of the inner zone/outer zone was evaluated in sham-operated control group $(9.1 \pm 2.0 \%)$ and treatment group $(10.3 \pm 3.3 \%)$, there was no significant difference between two groups ( $n=6$ per group; Figure S2B).

3.3. In Vivo Reprogramming Factor Expression Increases the Number of New Neurons but Not Astrocytes in the Hippocampus. To determine the density of proliferating cells in the subgranular zone of the hippocampus, $\mathrm{BrdU}^{+}$cells were counted. The number of $\mathrm{BrdU}^{+}$cells in the treatment group $(17.6 \pm 1.9 \times$ $10^{3}$ cells) was significantly 2.2 times higher than in the control group $\left(8.1 \pm 2.0 \times 10^{3}\right.$ cells $)(t=3.528, p<0.05$; Figure $3(\mathrm{a}))$. Meanwhile, to evaluate the cell fate of proliferating cells in the hippocampus, double-staining of cells with BrdU and cell type-specific markers such as $\beta$ III-tubulin (Tuj1, early neuronal marker), NeuN (mature neuronal maker), or GFAP (astrocyte marker) was performed. The numbers of $\mathrm{BrdU}^{+} \beta \mathrm{III}-$ tubulin ${ }^{+}$cells in the treatment group $(9.2 \pm 2.3 \times$ $10^{3}$ cells) were significantly 3.1 times higher than in the control group $\left(3.0 \pm 1.6 \times 10^{3}\right.$ cells $)(t=2.450, p<0.05$; Figures 3(b), 3(d), and 3(e)), indicating that the in vivo expression of reprogramming factors enhanced neurogenesis. The number of $\mathrm{BrdU}^{+} \mathrm{NeuN}^{+}$cells in the treatment group $\left(13.2 \pm 5.0 \times 10^{3}\right.$ cells) was also significantly 6.2 times higher than in the control group $\left(2.1 \pm 1.5 \times 10^{3}\right.$ cells $)(t=2.297, p<0.05$; Figures $3(\mathrm{c}), 3(\mathrm{f})$, and $3(\mathrm{~g})$ ), suggesting that the newly generated neurons differentiate into mature neurons. However, there were no $\mathrm{BrdU}^{+} \mathrm{GFAP}^{+}$cells in the hippocampus in either group suggesting that neurogenesis in the hippocampus is towards neurons, not astrocytes. The number of $\mathrm{BrdU}^{+}$cells of two weeks after the surgical treatment groups is shown in Figure S1. The above values are described in Table 1.

3.4. In Vivo Expression of Reprogramming Factors Increases the Number of Neural Precursor Cells in the Subventricular Zone. To determine the density of proliferating cells in the SVZ of the lateral ventricle, $\mathrm{BrdU}^{+}$cells were counted. The number of $\mathrm{BrdU}^{+}$cells in the treatment group $\left(57.7 \pm 4.1 \times 10^{3}\right.$ cells $)$ was 2.0 times higher than in the control group $\left(29.6 \pm 7.4 \times 10^{3}\right.$ cells) $(t=3.596, p<0.01$; Figure $4(\mathrm{a}))$. Meanwhile, to evaluate the proliferating cells in the SVZ, double-staining of cells with BrdU and cell type-specific markers such as Nestin (neural progenitor marker) and GFAP was used. The numbers of BrdU ${ }^{+}$Nestin $^{+}$cells in the treatment group (15.3 \pm $2.6 \times 10^{3}$ cells) were 4.3 times higher than in the control group $\left(3.6 \pm 1.5 \times 10^{3}\right.$ cells) $(t=3.868, p<0.01$; Figures $4(\mathrm{~b}), 4(\mathrm{~d})$, and $4(\mathrm{e})$ ), indicating that the in vivo expression of reprogramming factors increased newly generated neural precursor cells. The number of $\mathrm{BrdU}^{+} \mathrm{GFAP}^{+}$cells in the treatment group $\left(16.5 \pm 4.8 \times 10^{3}\right.$ cells) was also 2.9 times higher than in the control group $\left(5.7 \pm 2.0 \times 10^{3}\right.$ cells $)(t=2.631$, $p<0.05$; Figures $4(\mathrm{c}), 4(\mathrm{f})$, and $4(\mathrm{~g}))$, suggesting that the in vivo expression of reprogramming factors increased neural precursor cells and/or immature astrocytes in the SVZ. The above results are described in Table 1.

3.5. In Vivo Expression of Reprogramming Factors Increases Synapse Density in the Hippocampus. We evaluated expression levels of a presynaptic maker (synaptophysin) and postsynaptic marker (PSD-95) to determine if reprogramming factor expression increased density of synapse in the hippocampus. Using qRT-PCR, we confirmed that the level 


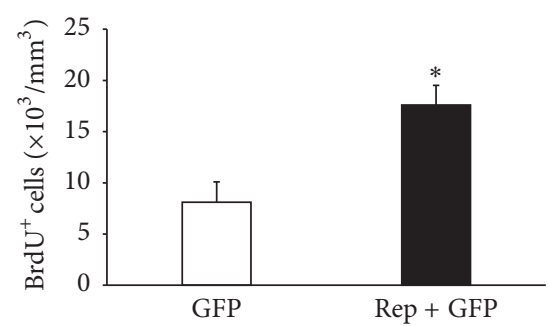

(a)

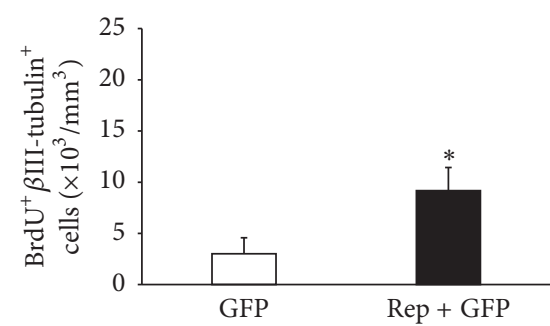

(b)

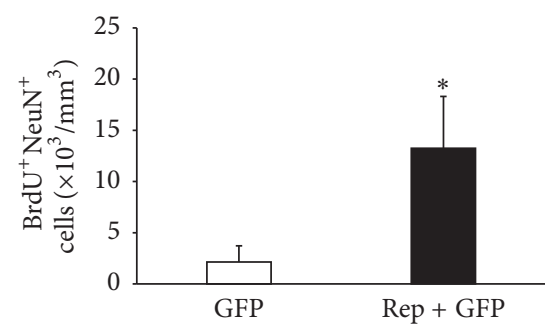

(c)

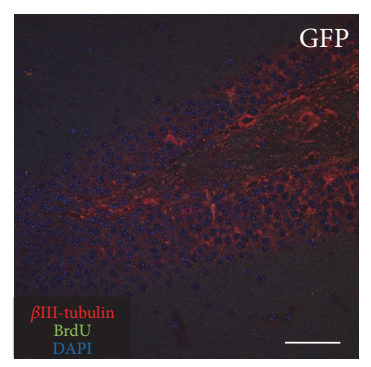

(d)

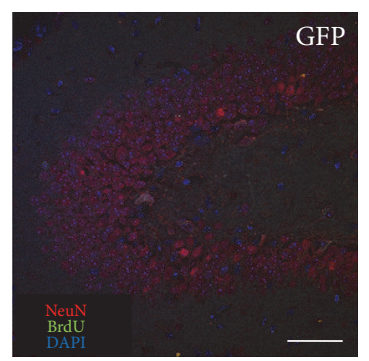

(f)

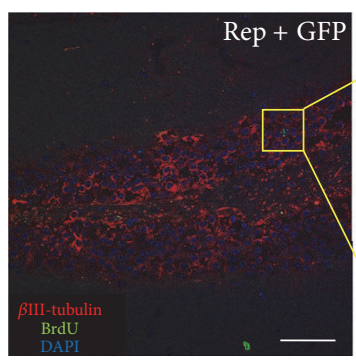

(e)

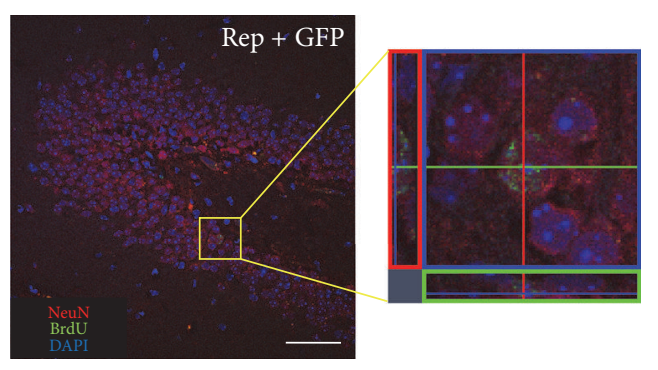

(g)

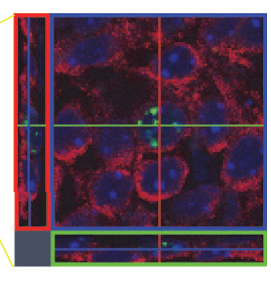

FIGURE 3: The number of new neurons in the hippocampus increased by in vivo expression of reprogramming factors. At postnatal 6 weeks, mice were injected with viral vector expressed GFP only (control group) or the four reprogramming factors and GFP (treatment group). To identify newly generated cells, mice were injected daily with 5-bromo-2-deoxyuridine (BrdU) up to 12 days. Eight weeks after injection, histological evaluations were performed. (a) The density of $\mathrm{BrdU}^{+}$cells in the hippocampus was significantly higher in the treatment group than in the control group $(t=3.528, p<0.05)$. (b-c) The density of newly generated neurons was determined through confocal microscopy by calculating the density of cells triple positive for DAPI (blue, nuclei), BrdU (green), and cell type-specific markers such as $\beta$ III-tubulin and NeuN. The densities of $\mathrm{BrdU}^{+} \beta$ III-tubulin ${ }^{+}$(b) and $\mathrm{BrdU}^{+} \mathrm{NeuN}^{+}$(c) cells were significantly higher in the treatment group than the control group $(t=2.450, p<0.05$ and $t=2.297, p<0.05$, resp.). (d-g) Confocal microscope images are immunohistochemistry results. (e, g) Cells with triple positive for DAPI, BrdU, and cell type-specific markers are indicated in the yellow box at the right panel. Scale bars $=50 \mu \mathrm{m}$. ${ }^{*} p<0.05$.

of PSD-95 was higher in the treatment group than the control group $(1.3 \pm 0.1$-fold, $t=2.879$, and $p<0.01$; Figure $5(\mathrm{a}))$. We also confirmed that the level of synaptophysin was higher in the treatment group than the control group $(1.4 \pm 0.1$-fold, $t=3.668$, and $p<0.01$; Figure 5(a)). Using western blot analysis, we confirmed that the level of PSD-95 was higher in the treatment group than the control group (1.6 \pm 0.1 -fold, $t=6.499$, and $p<0.001$; Figure 5(b)). We also confirmed that the level of synaptophysin was higher in the treatment group than the control group $(1.3 \pm 0.1$-fold, $t=3.136$, and $p<$ 0.01; Figure 5(b)). Confocal images also showed that PSD-95 expression was higher in the treatment group (Figures 5(c) and $5(\mathrm{~d})$ ). These results suggest that in vivo reprogramming therapy increases hippocampal synaptic plasticity in chronic hypoxic-ischemic brain injury.

\section{Discussion}

In our study, the reprogramming factors such as Oct4, Sox2, $\mathrm{c}-M y c$, and $K l f 4$ were delivered by intraventricular injection of viral vector, and expression of GFP was confirmed in the lateral ventricle near the dentate gyrus. Nakatomi et al. [29] reported that, following ischemic brain injury, adult neural progenitors can be encouraged in situ by intraventricular infusion of growth factors to substitute CA1 pyramidal neurons in the hippocampus. Intraventricular infusion of growth factors recruited the endogenous progenitor in situ, so making huge regeneration of pyramidal neurons after ischemia because hippocampal CA1 pyramidal neurons undertake general degeneration following temporary ischemia [3032]. Using a similar appoach, activated neuronal progenitor 


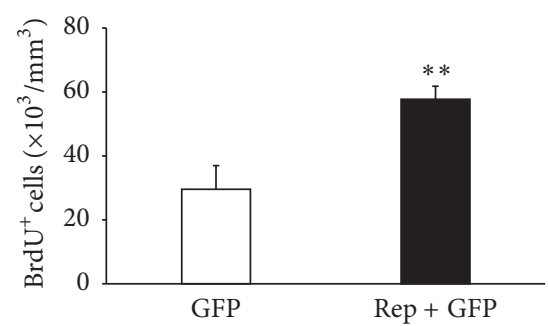

(a)

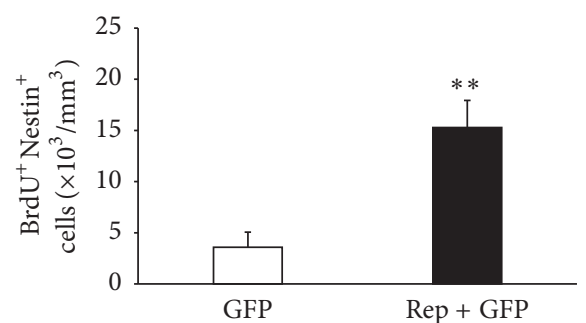

(b)

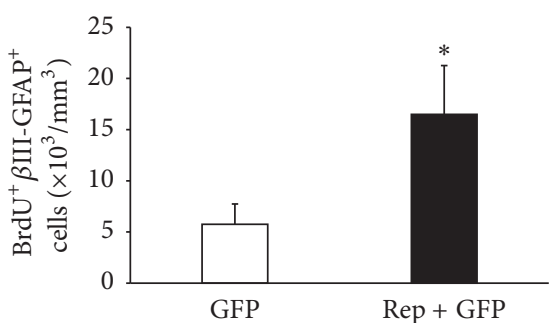

(c)

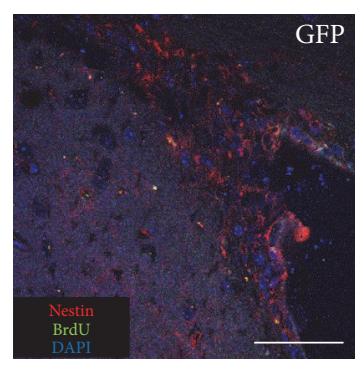

(d)

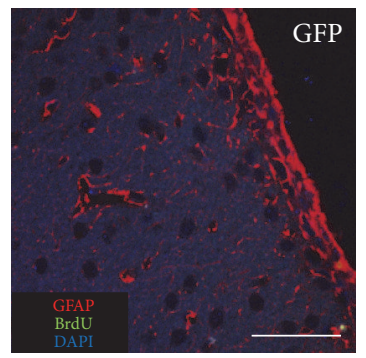

(f)
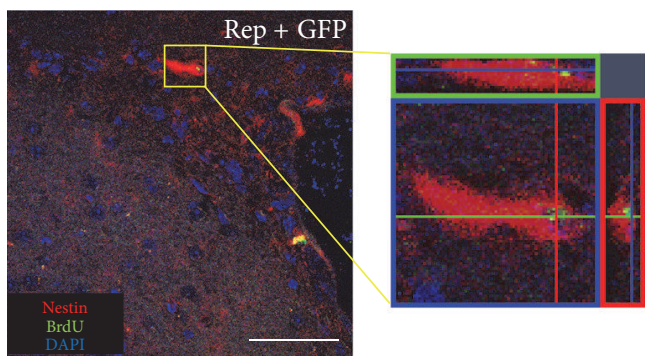

(e)
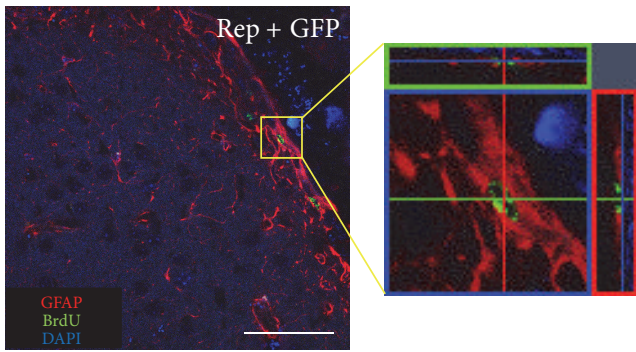

(g)

FIGURE 4: The number of neural progenitor cells in the subventricular zone increased by the in vivo expression of reprogramming factors. (a) The density of BrdU ${ }^{+}$cells in the subventricular zone was significantly higher in the treatment group than the control group $(t=3.596$, $p<0.01$ ). (b-c) The density of neural progenitor cells was determined through confocal microscopy by calculating the density of cells triple positive for DAPI (blue, nuclei), BrdU (green), and cell type-specific markers such as Nestin and GFAP. The densities of BrdU ${ }^{+} \mathrm{Nestin}^{+}$cells (b) and $\mathrm{BrdU}^{+} \mathrm{GFAP}^{+}$cells (c) were significantly higher in the treatment group than the control group $(t=3.868, p<0.01$ and $t=2.631$, $p<0.05$, resp.). (d-g) Confocal microscope images are immunohistochemistry results. (e, g) Cells with triple positive for DAPI, BrdU, and cell type-specific markers are indicated in the yellow box at the right panel. Scale bars $=50 \mu \mathrm{m} .{ }^{*} p<0.05 ;{ }^{* *} p<0.01$.

cells in the subgranular zone of the dentate gyrus migrate and differentiate into new neurons [33], and subependymal progenitors of the lateral ventricular wall might increase the movement to the pools of neurogenic progenitors in the hippocampus of the mammalian brain $[12,34,35]$. Taken together, these results suggest that hippocampal neurogenesis might be increased by delivering reprogramming factors into the lateral ventricle.

Histological analysis in the hippocampus showed that the in vivo expression of reprogramming factors enhanced the proliferative generation of neurons, but not astrocytes. In a previous study, when double-labeling was performed, approximately $60 \%$ of $\mathrm{BrdU}^{+}$cells in the granule cell layer were also NeuN double-stained, indicating differentiation into neurons. None of the $\mathrm{BrdU}^{+}$cells in the granule cell layer appeared to differentiate into $\mathrm{GFAP}^{+}$astrocytes [36]. However, it cannot be ruled out that these cells could be also derived from other cell types because in vivo overexpression of reprogramming factors can epigenetically activate cells so that they are in an intermediate plastic state that allows them to have an alternative fate [37-41]. Tentatively, our study demonstrated that four reprogramming factors may influence endogenous progenitors in the hippocampus to differentiate into mature neurons.

In addition, histological analysis in the SVZ showed that the in vivo expression of reprogramming factors increased the neural precursor cells. In the SVZ, stem cell astrocyte marker (type B cells, glial fibrillary acidic protein expressing (GFAP)) also shared neural stem cell marker (Nestin) [42, 43]. Thus, the $\mathrm{GFAP}^{+}$cells generated by reprogramming factor expression might be a novel cell source with stem cell potential in the SVZ of the injured brain [28, 43].

For the learning of new memories, hippocampal neurogenesis may be essential [44]. Both learning and the affective state are related to the alteration of adult hippocampal neurogenesis [45]. In previous studies, genetic ablation of new 

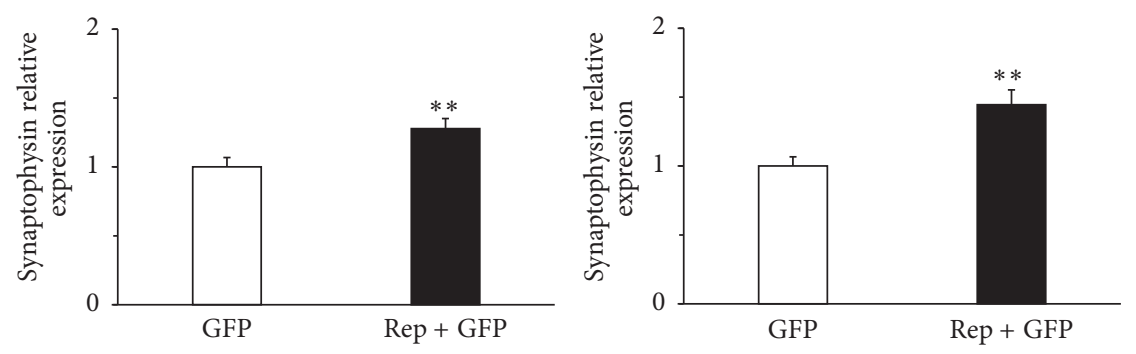

(a)
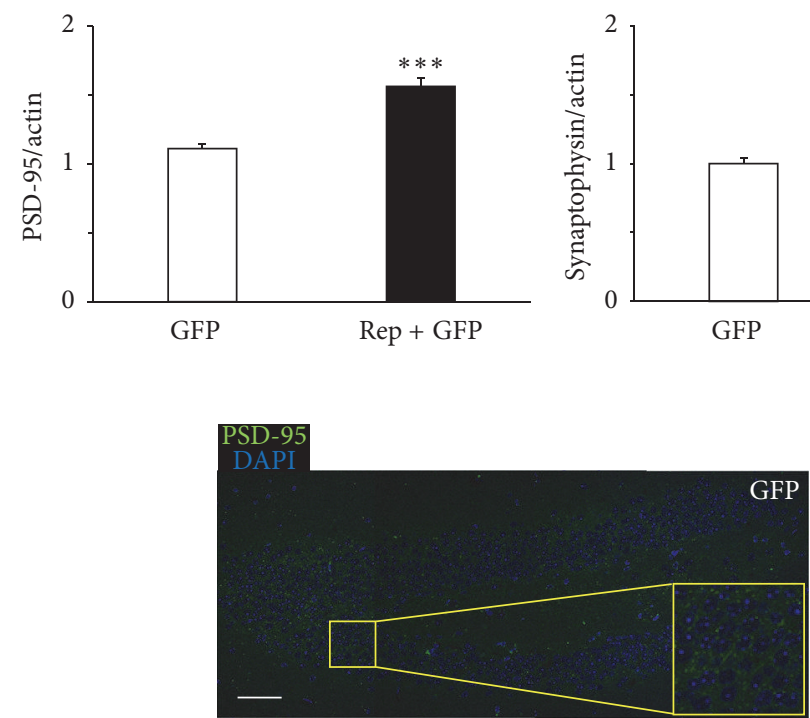

(c)
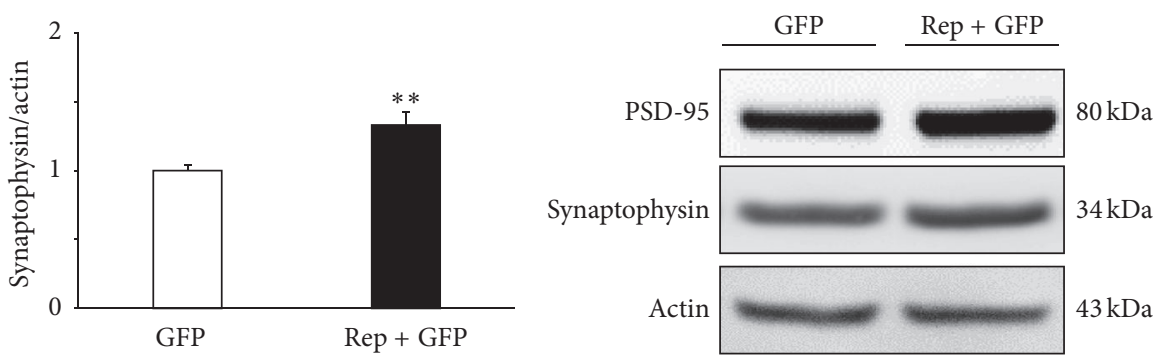

(b)

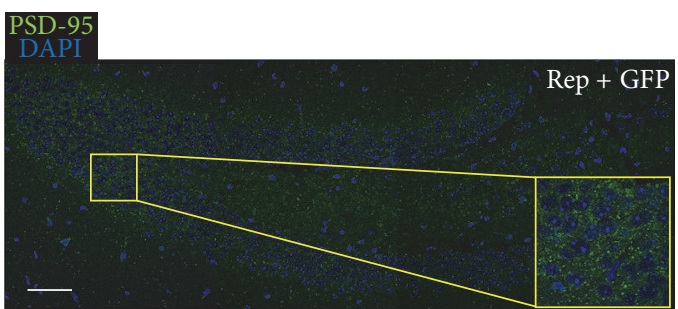

(d)

FIGURE 5: Synaptic density in the hippocampus increased by in vivo expression of reprogramming factors. The expression levels of the synaptic markers of PSD-95 and synaptophysin in the hippocampus were determined by quantitative real-time reverse transcription-polymerase chain reaction (qRT-PCR) and western blot ( $n=3$ per group). (a) qRT-PCR analysis confirmed that PSD-95 and synaptophysin levels were significantly higher in the treatment group than the control group $(t=2.879, p<0.01 ; t=3.668, p<0.01$, resp.). (b) Western blot analysis also confirmed that PSD-95 and synaptophysin levels were significantly higher in the treatment group than the control group $(t=6.499$, $p<0.001 ; t=3.136, p<0.01$, resp.). (c, d) Confocal microscope images are immunohistochemistry results that showed the area of the dentate gyrus in the hippocampus. The expression of PSD-95 in the yellow box represented the difference of synaptic density in the control (c) and treatment (d) group. Scale bars $=50 \mu \mathrm{m} .{ }^{* *} p<0.01{ }^{* * *} p<0.001$.

neurons in the hippocampus was associated with learning and memory impairment, while induction of hippocampal neurogenesis alleviated such lesion-induced impairment $[46,47]$. Therefore, new neurons in hippocampus play an important role in the hippocampus-related behaviors such as learning and memory [48]. In particular, an increase in neurogenesis, and thus an increase in neural plasticity, may improve performance in learning and memory tasks [44]. Conversely, blocking neurogenesis may be the cause of the observable decline in performance in various learning- and memory-related tasks [44].

In our study, a ratio of distance in the center and periphery was recorded as an index of anxiety. When a mouse is placed in a foreign environment, it intends to stay in the outer zone. After it adapts in the environment and its anxiety decreases, the spending time and distance increase in the inner zone. Therefore, increase of spending time or distance in the central part and of the ratio central over total locomotion indicates decrease of anxiety [27]. Several researchers have suggested a link between hippocampal neurogenesis and anxiety-related behaviors. Revest et al. convincingly explained the connection between neurogenesis and anxietyrelated behavior [49]. In that study, the authors demonstrated that deficits in hippocampal neurogenesis via specific ablation of newborn neurons in the adult dentate gyrus resulted in anxious behavior [50]. Furthermore, Dias and colleagues also found a decreased number of immature neurons in the dentate gyrus of a rodent model with generalized anxiety [51]. Consistent with the previous studies [44-51], we confirmed that the in vivo expression of reprogramming factors facilitated hippocampal neurogenesis and hippocampus-related behavioral outcomes such as increased long-term memory and decreased anxiety-related behavior. Additionally, when neurobehavioral tests were performed in sham-operated control group and treatment group, there was no significant difference between two groups. Therefore, it showed that the in vivo expression of reprogramming factors might be effective in the microenvironment of the injured brain. 
Our qRT-PCR, western blotting, and immunohistochemistry results showed that in vivo reprogramming therapy increased expression of synaptic proteins such as the presynaptic marker, synaptophysin, and postsynaptic marker, PSD-95, relative to the control group. PSD-95 is a core component of the PSD and a key molecule in mature synapses [52]. Moreover, maturation of synapse-presynaptic terminal and postsynaptic component-can be labeled by PSD-95 [53]. In previous studies, targeted disruption of PSD-95 alters activity-dependent synaptic plasticity and learning. The reason of why PSD-95 mutant mice are impaired in spatial learning can be explained by these abnormalities in synaptic plasticity $[54,55]$. In addition, PSD-95 mutant mice exhibit severe deficits in spatial, working, and distress memory and abnormal anxiety, and behaviors are likely to be related to abnormal synaptic transmission in the hippocampus, especially dentate gyrus synapses [52]. Here we confirmed that increased expression of PSD-95 and synaptophysin was related to improved long-term memory and decreased anxiety due to enhanced synaptic plasticity.

\section{Conclusions}

Taken together, the in vivo expression of four reprogramming factors improved long-term memory and decreased anxiety in the animal model of chronic hypoxic-ischemic brain injury. Recovery of hippocampus-related behavior was associated with enhanced hippocampal neurogenesis and synaptic plasticity.

\section{Competing Interests}

The authors declare that there is no conflict of interests regarding the publication of this paper.

\section{Acknowledgments}

This study was supported by grants from the National Research Foundation (NRF-2014R1A2A1A11052042; 2015M3A9B4067068) and the Korea Health Technology R\&D Project through the Korea Health Industry Development Institute (KHIDI), funded by the Ministry of Health \& Welfare, Republic of Korea (HI16C1012), and from the "Dongwha" Faculty Research Assistance Program of Yonsei University College of Medicine (6-2016-0126).

\section{References}

[1] J. Altman and G. D. Das, "Autoradiographic and histological evidence of postnatal hippocampal neurogenesis in rats," Journal of Comparative Neurology, vol. 124, no. 3, pp. 319-335, 1965.

[2] W. Deng, J. B. Aimone, and F. H. Gage, "New neurons and new memories: how does adult hippocampal neurogenesis affect learning and memory?" Nature Reviews Neuroscience, vol. 11, no. 5, pp. 339-350, 2010.

[3] F. H. Gage, "Mammalian neural stem cells," Science, vol. 287, no. 5457, pp. 1433-1438, 2000.
[4] Y. Zhang, M. Chopp, Y. Meng et al., "Cerebrolysin improves cognitive performance in rats after mild traumatic brain injury," Journal of neurosurgery, vol. 122, no. 4, pp. 843-855, 2015.

[5] C. Zhao, W. Deng, and F. H. Gage, "Mechanisms and functional implications of adult neurogenesis," Cell, vol. 132, no. 4, pp. 645660, 2008.

[6] J. H. Yu, J. H. Seo, J. Y. Lee, M. Y. Lee, and S. R. Cho, "Induction of neurorestoration from endogenous stem cells," Cell Transplantation, vol. 25, no. 5, pp. 863-882, 2016.

[7] O. Arias-Carrion and R. Drucker-Colin, "Neurogenesis as a therapeutic strategy to regenerate central nervous system," Revue Neurologique, vol. 45, no. 12, pp. 739-745, 2007.

[8] O. Arias-Carrión, N. Freundlieb, W. H. Oertel, and G. U. Höglinger, "Adult neurogenesis and Parkinson's disease," CNS \& Neurological Disorders-Drug Targets, vol. 6, no. 5, pp. 326335, 2007.

[9] A. Arvidsson, T. Collin, D. Kirik, Z. Kokaia, and O. Lindvall, "Neuronal replacement from endogenous precursors in the adult brain after stroke," Nature Medicine, vol. 8, no. 9, pp. 963970, 2002.

[10] K. Jin, M. Minami, J. Q. Lan et al., "Neurogenesis in dentate subgranular zone and rostral subventricular zone after focal cerebral ischemia in the rat," Proceedings of the National Academy of Sciences of the United States of America, vol. 98, no. 8, pp. 4710-4715, 2001.

[11] T. Yamashita, M. Ninomiya, P. Hernandez Acosta et al., "Subventricular zone-derived neuroblasts migrate and differentiate into mature neurons in the post-stroke adult striatum," The Journal of Neuroscience, vol. 26, no. 24, pp. 6627-6636, 2006.

[12] S. A. Goldman, "Disease targets and strategies for the therapeutic modulation of endogenous neural stem and progenitor cells," Clinical Pharmacology and Therapeutics, vol. 82, no. 4, pp. 453460, 2007.

[13] L. Ruan, B. Wang, Q. Zhuge, and K. Jin, "Coupling of neurogenesis and angiogenesis after ischemic stroke," Brain Research, vol. 1623, pp. 166-173, 2015.

[14] K. Takahashi and S. Yamanaka, "Induction of pluripotent stem cells from mouse embryonic and adult fibroblast cultures by defined factors," Cell, vol. 126, no. 4, pp. 663-676, 2006.

[15] Z. D. Smith, I. Nachman, A. Regev, and A. Meissner, "Dynamic single-cell imaging of direct reprogramming reveals an early specifying event," Nature Biotechnology, vol. 28, no. 5, pp. 521526, 2010.

[16] T. S. Mikkelsen, J. Hanna, X. Zhang et al., "Dissecting direct reprogramming through integrative genomic analysis," Nature, vol. 454, no. 7200, pp. 49-55, 2008.

[17] S. H. Im, J. H. Yu, E. S. Park et al., "Induction of striatal neurogenesis enhances functional recovery in an adult animal model of neonatal hypoxic-ischemic brain injury," Neuroscience, vol. 169, no. 1, pp. 259-268, 2010.

[18] R. C. Vannucci, J. R. Connor, D. T. Mauger et al., "Rat model of perinatal hypoxic-ischemic brain damage," Journal of Neuroscience Research, vol. 55, no. 2, pp. 158-163, 1999.

[19] J. Y. Yager, "Animal models of hypoxic-ischemic brain damage in the newborn," Seminars in Pediatric Neurology, vol. 11, no. 1, pp. 31-46, 2004.

[20] J. H. Seo, H. Kim, E. S. Park et al., "Environmental enrichment synergistically improves functional recovery by transplanted adipose stem cells in chronic hypoxic-ischemic brain injury," Cell Transplantation, vol. 22, no. 9, pp. 1553-1568, 2013. 
[21] N. S. Jiwa, P. Garrard, and A. H. Hainsworth, "Experimental models of vascular dementia and vascular cognitive impairment: a systematic review," Journal of Neurochemistry, vol. 115, no. 4, pp. 814-828, 2010.

[22] Y. Yamamoto, N. Shioda, F. Han et al., "Nobiletin improves brain ischemia-induced learning and memory deficits through stimulation of CaMKII and CREB phosphorylation," Brain Research, vol. 1295, pp. 218-229, 2009.

[23] M.-Y. Lee, J. H. Yu, J. Y. Kim et al., "Alteration of synaptic activity-regulating genes underlying functional improvement by long-term exposure to an enriched environment in the adult brain," Neurorehabilitation and Neural Repair, vol. 27, no. 6, pp. 561-574, 2013.

[24] V. H. Denenberg, "Open-field behavior in the rat: what does it mean?" Annals of the New York Academy of Sciences, vol. 159, no. 3, pp. 852-859, 1969.

[25] R. N. Walsh and R. A. Cummins, “The open-field test: a critical review," Psychological Bulletin, vol. 83, no. 3, pp. 482-504, 1976.

[26] V. Carola, F. D’Olimpio, E. Brunamonti, F. Mangia, and P. Renzi, "Evaluation of the elevated plus-maze and open-field tests for the assessment of anxiety-related behaviour in inbred mice," Behavioural Brain Research, vol. 134, no. 1-2, pp. 49-57, 2002.

[27] L. Prut and C. Belzung, "The open field as a paradigm to measure the effects of drugs on anxiety-like behaviors: a review," European Journal of Pharmacology, vol. 463, no. 1-3, pp. 3-33, 2003.

[28] J. H. Seo, M. Y. Lee, J. H. Yu et al., "In situ pluripotency factor expression promotes functional recovery from cerebral ischemia," Molecular Therapy, vol. 24, no. 9, pp. 1538-1549, 2016.

[29] H. Nakatomi, T. Kuriu, S. Okabe et al., "Regeneration of hippocampal pyramidal neurons after ischemic brain injury by recruitment of endogenous neural progenitors," Cell, vol. 110, no. 4, pp. 429-441, 2002.

[30] T. Kirino, "Delayed neuronal death in the gerbil hippocampus following ischemia," Brain Research, vol. 239, no. 1, pp. 57-69, 1982.

[31] W. A. Pulsinelli, J. B. Brierley, and F. Plum, "Temporal profile of neuronal damage in a model of transient forebrain ischemia," Annals of Neurology, vol. 11, no. 5, pp. 491-498, 1982.

[32] M.-L. Smith, R. N. Auer, and B. K. Siesjö, "The density and distribution of ischemic brain injury in the rat following 2-10 min of forebrain ischemia," Acta Neuropathologica, vol. 64, no. 4, pp. 319-332, 1984.

[33] T. D. Palmer, J. Takahashi, and F. H. Gage, "The adult rat hippocampus contains primordial neural stem cells," Molecular and Cellular Neurosciences, vol. 8, no. 6, pp. 389-404, 1996.

[34] S. Goldman, "Glia as neural progenitor cells," Trends in Neurosciences, vol. 26, no. 11, pp. 590-596, 2003.

[35] F. Doetsch, L. Petreanu, I. Caille, J.-M. Garcia-Verdugo, and A. Alvarez-Buylla, "EGF converts transit-amplifying neurogenic precursors in the adult brain into multipotent stem cells," Neuron, vol. 36, no. 6, pp. 1021-1034, 2002.

[36] F. R. Sharp, J. Liu, and R. Bernabeu, "Neurogenesis following brain ischemia," Developmental Brain Research, vol. 134, no. 1-2, pp. 23-30, 2002.

[37] J. A. Efe, S. Hilcove, J. Kim et al., "Conversion of mouse fibroblasts into cardiomyocytes using a direct reprogramming strategy," Nature Cell Biology, vol. 13, no. 3, pp. 215-222, 2011.
[38] L. Kurian, I. Sancho-Martinez, E. Nivet et al., "Conversion of human fibroblasts to angioblast-like progenitor cells," Nature Methods, vol. 10, no. 1, pp. 77-83, 2013.

[39] S. Zhu, M. Rezvani, J. Harbell et al., "Mouse liver repopulation with hepatocytes generated from human fibroblasts," Nature, vol. 508, no. 7494, pp. 93-97, 2014.

[40] J. Ladewig, P. Koch, and O. Brüstle, "Leveling Waddington: the emergence of direct programming and the loss of cell fate hierarchies," Nature Reviews Molecular Cell Biology, vol. 14, no. 4, pp. 225-236, 2013.

[41] J. Kim, R. Ambasudhan, and S. Ding, "Direct lineage reprogramming to neural cells," Current Opinion in Neurobiology, vol. 22, no. 5, pp. 778-784, 2012.

[42] P. A. Riquelme, E. Drapeau, and F. Doetsch, "Brain microecologies: neural stem cell niches in the adult mammalian brain," Philosophical Transactions of the Royal Society B: Biological Sciences, vol. 363, no. 1489, pp. 123-137, 2008.

[43] S. Robel, B. Berninger, and M. Götz, “The stem cell potential of glia: lessons from reactive gliosis," Nature Reviews Neuroscience, vol. 12, no. 2, pp. 88-104, 2011.

[44] Y. Kitabatake, K. A. Sailor, G.-L. Ming, and H. Song, "Adult neurogenesis and hippocampal memory function: new cells, more plasticity, new memories?" Neurosurgery Clinics of North America, vol. 18, no. 1, pp. 105-113, 2007.

[45] S. S. Newton and R. S. Duman, "Regulation of neurogenesis and angiogenesis in depression," Current Neurovascular Research, vol. 1, no. 3, pp. 261-267, 2004.

[46] I. Imayoshi, M. Sakamoto, T. Ohtsuka et al., "Roles of continuous neurogenesis in the structural and functional integrity of the adult forebrain," Nature Neuroscience, vol. 11, no. 10, pp.1153$1161,2008$.

[47] Y.-W. Tsai, Y.-R. Yang, P. S. Wang, and R.-Y. Wang, "Intermittent hypoxia after transient focal ischemia induces hippocampal neurogenesis and c-Fos expression and reverses spatial memory deficits in rats," PLoS ONE, vol. 6, no. 8, article e24001, 2011.

[48] Y.-W. Tsai, Y.-R. Yang, S. H. Sun, K.-C. Liang, and R.-Y. Wang, "Post ischemia intermittent hypoxia induces hippocampal neurogenesis and synaptic alterations and alleviates longterm memory impairment," Journal of Cerebral Blood Flow and Metabolism, vol. 33, no. 5, pp. 764-773, 2013.

[49] J.-M. Revest, D. Dupret, M. Koehl et al., "Adult hippocampal neurogenesis is involved in anxiety-related behaviors," Molecular Psychiatry, vol. 14, no. 10, pp. 959-967, 2009.

[50] A. A. Marques, M. C. Bevilaqua, A. M. da Fonseca, A. E. Nardi, S. Thuret, and G. P. Dias, "Gender differences in the neurobiology of anxiety: focus on adult hippocampal neurogenesis," Neural Plasticity, vol. 2016, Article ID 5026713, 14 pages, 2016.

[51] G. P. Dias, M. C. D. N. Bevilaqua, A. C. D. S. Da Luz et al., "Hippocampal biomarkers of fear memory in an animal model of generalized anxiety disorder," Behavioural Brain Research, vol. 263, pp. 34-45, 2014.

[52] H. Nagura, Y. Ishikawa, K. Kobayashi et al., "Impaired synaptic clustering of postsynaptic density proteins and altered signal transmission in hippocampal neurons, and disrupted learning behavior in PDZ1 and PDZ2 ligand binding-deficient PSD-95 knockin mice," Molecular Brain, vol. 5, no. 1, article 43, 2012.

[53] A. E.-D. El-Husseini, E. Schnell, D. M. Chetkovich, R. A. Nicoll, and D. S. Bredt, "PSD-95 involvement in maturation of excitatory synapses,” Science, vol. 290, no. 5495, pp. 1364-1368, 2000 . 
[54] M. Migaud, P. Charlesworth, M. Dempster et al., "Enhanced long-term potentiation and impaired learning in mice with mutant postsynaptic density-95 protein," Nature, vol. 396, no. 6710, pp. 433-439, 1998.

[55] A. E.-D. El-Husseini, E. Schnell, S. Dakoji et al., "Synaptic strength regulated by palmitate cycling on PSD-95," Cell, vol. 108, no. 6, pp. 849-863, 2002. 

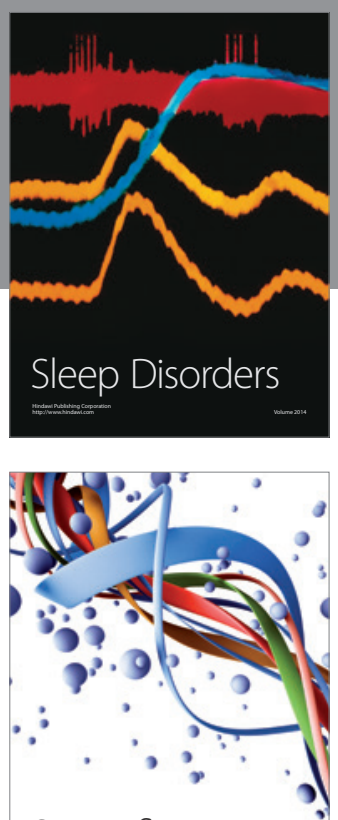

Scientifica
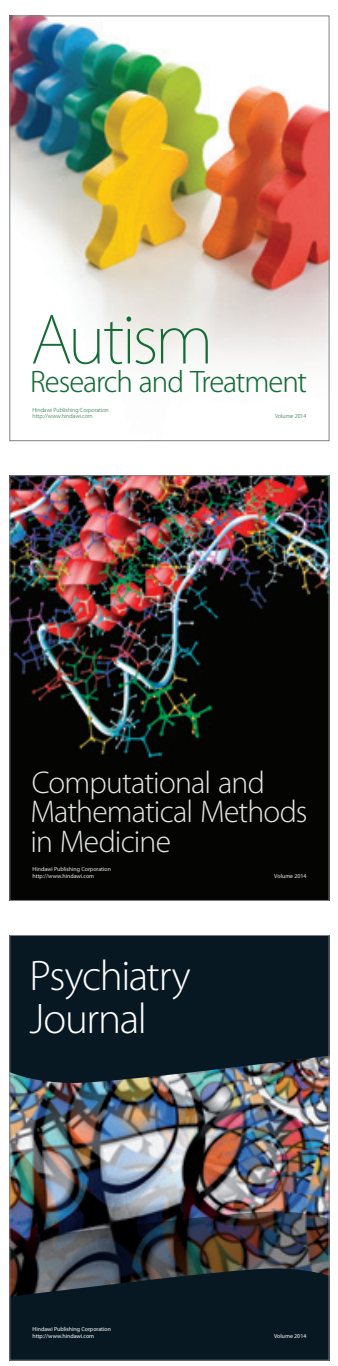
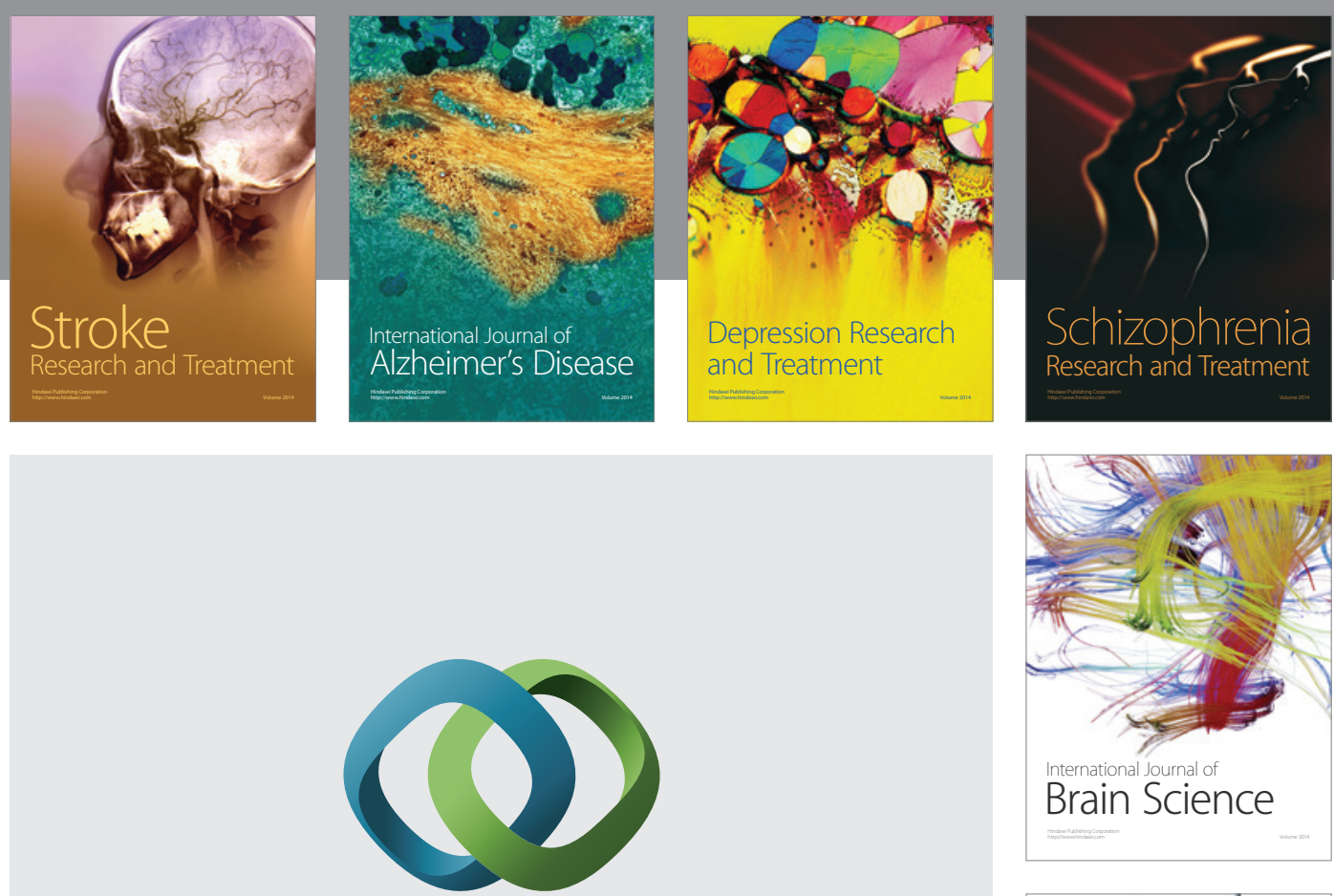

\section{Hindawi}

Submit your manuscripts at

http://www.hindawi.com
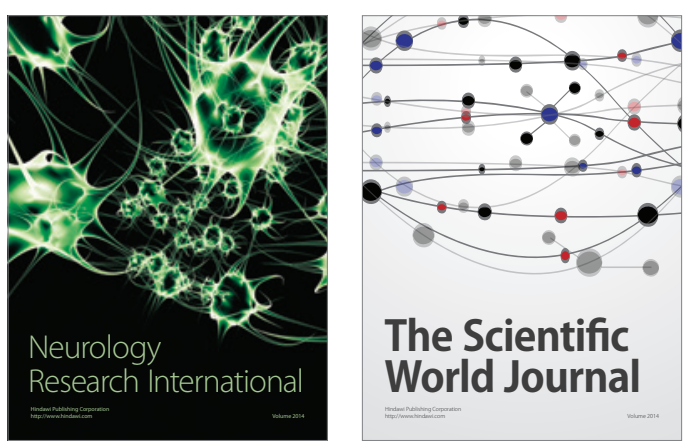

The Scientific World Journal

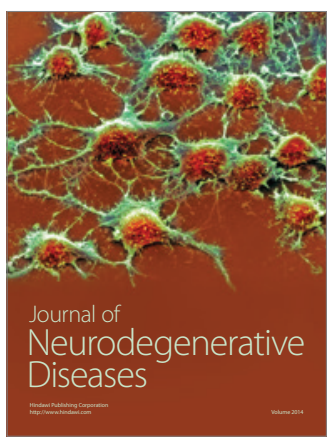

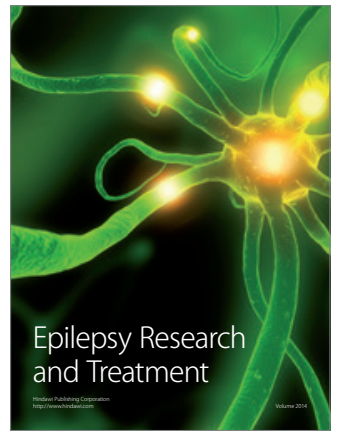

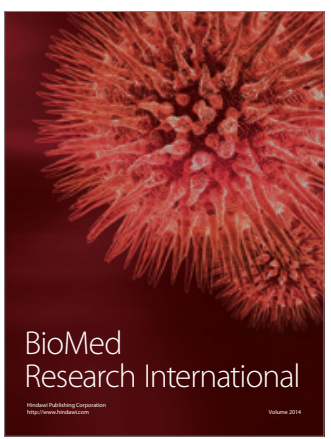

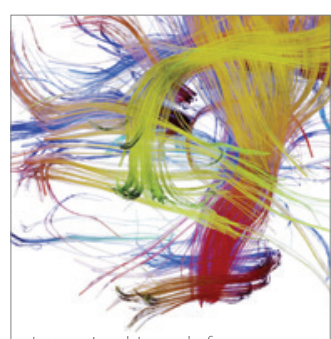

Brain Science

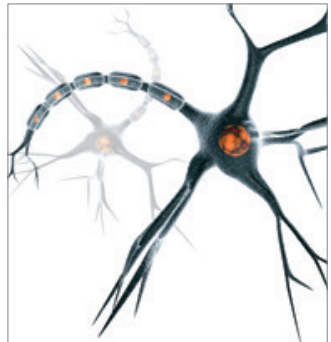

Neural Plasticity
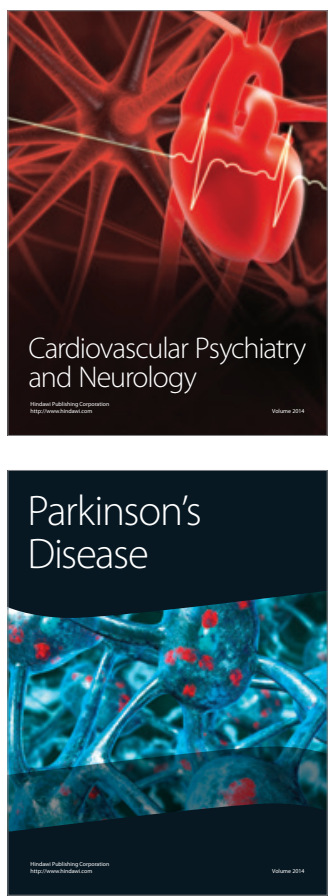